\title{
Endometrial and decidual stromal precursors show a different decidualization capacity
}

\author{
Maria Jose Ruiz Magaña ${ }^{1}$, Jose Maria Puerta² ${ }^{2}$ Rocio Martínez-Aguilar ${ }^{1}$, Tatiana Llorca \\ Osmany Blanco ${ }^{3}$, Raquel Muñoz-Fernández ${ }^{1}$, Enrique G Olivares ${ }^{1,4,5}$ and Carmen Ruiz-Ruiz ${ }^{1,4}$ \\ 'Instituto de Biopatología y Medicina Regenerativa, Centro de Investigación Biomédica, Universidad de Granada, \\ Armilla, Granada, Spain, ${ }^{2}$ Servicio de Obstetricia y Ginecología, Hospital Universitario Virgen de las Nieves, \\ Granada, Spain, ${ }^{3}$ Bacteriología y Laboratorio Clínico, Facultad de Salud, Universidad de Santander, Bucaramanga, \\ Colombia, ${ }^{4}$ Departamento de Bioquímica y Biología Molecular III e Inmunología, Universidad de Granada, \\ Granada, Spain and ${ }^{5}$ Unidad de Gestión Clínica Laboratorios, Hospital Universitario Clínico San Cecilio, \\ Granada, Spain
}

Correspondence should be addressed to E G Olivares; Email: engarcia@ugr.es

\begin{abstract}
Endometrial stromal cells (EnSCs) and decidual stromal cells (DSCs) originate from fibroblastic precursors located around the vessels of the human nonpregnant endometrium and the pregnant endometrium (decidua), respectively. Under the effect of ovarian or pregnancy hormones, these precursors differentiate (decidualize), changing their morphology and secreting factors that appear to be essential for the normal development of pregnancy. However, the different physiological context - that is, non-pregnancy vs pregnancy - of those precursors (preEnSCs, preDSCs) might affect their phenotype and functions. In the present study, we established preEnSC and preDSC lines and compared the antigen phenotype and responses to decidualization factors in these two types of stromal cell line. Analyses with flow cytometry showed that preEnSCs and preDSCs exhibited a similar antigen phenotype compatible with that of bone marrow mesenchymal stem/stromal cells. The response to decidualization in cultures with progesterone and cAMP was evaluated by analyzing changes in cell morphology by microscopy, prolactin and IL-15 secretion by enzyme immunoassay and the induction of apoptosis by flow cytometry. In all four analyses, preDSCs showed a significantly higher response than preEnSCs. The expression of progesterone receptor (PR), protein kinase A (PKA) and FOXO1 was studied with Western blotting. Both types of cells showed similar levels of PR and PKA, but the increase in PKA RI subunit expression in response to decidualization was again significantly greater in preDSCs. We conclude that preEnSCs and preDSCs are equivalent cells but differ in their ability to decidualize. Functional differences between them probably derive from factors in their different milieus.

Reproduction (2020) 160 83-91
\end{abstract}

\section{Introduction}

Endometrial stromal cells (EnSCs) and decidual stromal cells (DSCs) are the main cellular components of the human nonpregnant endometrium and the pregnant endometrium (decidua), respectively. These stromal cells originate from fibroblastic precursors located around the vessels (Wynn 1974, Ferenczy \& Guralnick 1983) and are related to pericytes and mesenchymal stem/stromal cells (MSCs) (Dimitrov et al. 2010, Munoz-Fernandez et al. 2018, 2019). The latter two are considered analogous or identical cell types (da Silva Meirelles et al. 2008, 2016, Caplan \& Correa 2011). From their perivascular location, fibroblastic precursors secrete chemokines that may determine the different types of leukocytes in the endometrium and decidua (Munoz-Fernandez et al. 2018). A predecidual reaction, which begins close to the vessels and extends through the endometrium, occurs under the effect of ovarian hormones during the luteal phase of the menstrual cycle. In this reaction, fibroblastic precursors differentiate into decidualized EnSCs, changing their morphology to a rounder shape and secreting several distinctive factors such as prolactin (PRL) (Telgmann \& Gellersen 1998, Bergeron 2000). These cells are discarded during menstruation, but if pregnancy occurs, the process of precursor decidualization continues in the presence of pregnancy hormones (Wynn 1974, Ferenczy \& Guralnick 1983). This is essential for DSCs to acquire properties that allow embryo implantation, the control of trophoblast invasion and appropriate maternal-fetal immune relationships.

We and other authors have used the term 'predecidual stromal cells' (preDSCs) to refer to the perivascular stromal precursors in the decidua that differentiate into decidualized DSCs (Olivares et al. 1997, Kyurkchiev 
et al. 2010, Munoz-Fernandez et al. 2018). Likewise, stromal precursors in the nongestational endometrium can be referred to as preEnSCs. Therefore, preEnSCs and preDSCs can be hypothesized to correspond to the same type of cell in two different physiological situations: nonpregnancy and pregnancy. Nevertheless, a relevant point that needs to be ascertained is whether the gestational milieu, conditioned by the effect of local hormones, cytokines and growth factors, is associated with any phenotypic or functional changes in preDSCs compared to preEnSCs.

PreEnSCs, obtained from the endometrium or menstrual blood, and preDSCs, obtained from decidua, can be cultured in vitro to establish cell lines. This has made it possible to analyze the antigen phenotype and functions of these cells (Dimitrov et al. 2008, MunozFernandez et al. 2012, 2018). Furthermore, under the effects of progesterone (P4) and CAMP, stromal precursors decidualize in vitro as they do in vivo: the cells become rounder and secrete PRL (Huang et al. 1987, Olivares et al. 1997). Menstrual blood, although a wasting tissue, is an appropriate source of stromal cells that have been used in many basic and clinical studies (Hida et al. 2008, Zhong et al. 2009, Ulrich et al. 2013, Sugawara et al. 2014). In the work reported here, we established preEnSC lines from menstrual blood and preDSC lines from first-trimester decidua and compared the antigen phenotype and functions of these two types of cell line. As expected, they had similar phenotypic markers; however, they showed differences in the process of decidualization.

\section{Materials and methods}

\section{Samples}

For preDSC lines, samples from elective vaginal terminations of first-trimester pregnancies (6-11 weeks) were obtained from 20 healthy women. None of the abortions were pharmacologically induced. The specimens were obtained by suction curettage at the Clínica El Sur in Malaga or the Clínica Ginegranada in Granada. For the preEnSC lines, 21 healthy women donated menstrual blood samples. All women were aged 20 to 35 years, and those who were using any medication or with infectious, autoimmune or other systemic or local disease were excluded.

For MSC lines, leftover samples of bone marrow aspirates from seven hematologically normal donors were obtained at the Hospital de Baza (Baza, Granada).

All donors provided a written informed consent. The Research and Ethics Committee of the University of Granada approved the study.

\section{Isolation, culture and decidualization of cell lines}

To establish preDSC lines, we used the method described by Kimatrai et al. (2003). For preEnSC and MSC lines, the procedure started with the dilution in phosphate buffered saline (PBS) of menstrual blood and bone marrow aspirate samples, respectively, followed by centrifugation on a FicollPaque (Sigma-Aldrich) density gradient. Only preparations with $>95 \%$ viable cells, as determined by trypan blue exclusion, were used. Purified cells, confirmed by the co-expression of CD10 and CD29 (95-100\% positive cells) and the absence of CD45 and cytokeratin, were maintained and expanded in Opti-MEM medium (Invitrogen) with 3\% fetal calf serum (FCS). In this low serum-containing medium, cell lines showed a stable antigen phenotype and functional activities for 8-12 weeks (up to five passages) (Oliver et al. 1999, Garcia-Pacheco et al. 2001, Kimatrai et al. 2003, 2005). The maternal origin of each preDSC line was confirmed by comparison with its corresponding trophoblast obtained from the same sample, using short tandem repeat markers and quantitative-fluorescent PCR (Devyser AB, Hägersten, Sweden).

For decidualization, preDSC, preEnSC and MSC lines were cultured to $70 \%$ confluence and incubated in complete medium (OptiMEM plus 3\% FCS) with $300 \mathrm{nM} \mathrm{P4}$ and 500 $\mathrm{mM}$ 8-bromo-cAMP (Sigma-Aldrich) for up to 28 days. Every 3-4 days the culture medium was changed and the factors were added again (Leno-Duran et al. 2014).

\section{Antibodies}

The monoclonal antibodies (mAbs) used in this study for flow cytometry analysis were CD9-fluorescein isothiocyanate (FITC), CD10-phycoerythrin (PE), CD15-allophycocyanin (APC), CD19-PE, CD31-FITC, CD34-FITC, CD34-brilliant violet 421, CD44-FITC, CD45-FITC, CD62P-PE, CD73-PE, CD80-PE, CD86-APC, CD140b-PE, CD146, HLA-DR-PE, ICAM-1(CD54)-FITC, podoplanin-Alexa Fluor ${ }^{2}$ 647, VCAM-1 (CD106)-PE, W5C5-APC, cytokeratin (Biolegend, San Diego, CA, USA), CD13 (OKM13, Ortho Diagnostic Systems, Beerse, Belgium), CD29-APC (Caltag Laboratories, Burlingame, CA, USA), CD90-FITC (eBioscience, San Diego, CA, USA), CD140b, nestin, BAFF-FITC, CXCL13-APC (R\&D Systems), anti-alpha smooth muscle $(\alpha-S M)$ actin-FITC or cyanine 3 (Cy3) (Sigma-Aldrich) and HLA-G-APC (Abcam). The isotype controls were immunoglobulin IgM, IgG1-FITC, IgG1-PE, IgG1-APC or IgG2-PE (Biolegend). The secondary antibodies were FITC-labeled goat anti-mouse IgM and Alexa Fluor ${ }^{\circledR}$ 488-labeled goat anti-mouse IgG (Invitrogen). For Western blot analysis, we used anti-protein Kinase A (PKA) RI $\alpha \beta$ (which recognizes both Rl $\alpha$ and RI $\beta ; 1: 100$ ), anti-PKA $C \alpha / \beta / \gamma$ (which does not distinguish among $C \alpha, C \beta$ and $C \gamma ; 1: 100)$ antiprogesterone receptor (PR; 1:100) (Santa Cruz Biotechnology), anti-human Foxo1 antibody (1 $\mu \mathrm{g} / \mathrm{mL}$; R\&D Systems), antimouse IgG-horseradish peroxidase (HRP) (1:5000; Santa Cruz Biotechnology), anti-sheep IgG HRP-conjugated (1:1000; R\&D Systems), anti- $\beta$ actin (1:5000) and anti- $\alpha$-tubulin antibody (1:1000) (Sigma-Aldrich).

\section{Prolactin and IL-15 analysis}

The concentration of PRL and IL-15 in supernatants, collected from decidualized cells at the indicated times, was determined by enzyme immunoassay (Roche and R\&D Systems) according to the manufacturer's instructions. 


\section{Flow cytometry analysis}

Surface and intracellular antigens, as well as hypodiploid apoptotic cells, were studied in an FACScan cytometer as previously described (Blanco et al. 2009).

\section{Reverse transcription polymerase chain reaction (RT-PCR)}

Total RNA was extracted from cells with the TRIzol isolation method, and cDNA was synthesized with Oligo-dT primers and Moloney murine leukemia virus $\mathrm{H}$ minus ribonuclease reverse transcriptase (Invitrogen) according to the manufacturer's protocol. For RT-PCR, we used a 2720 Thermal Cycler (Applied Biosystems). The reaction mixture (total volume $20 \mu \mathrm{L}$ ) contained cDNA (the equivalent of 100 ng RNA), $200 \mathrm{nM}$ deoxy-NTPs, $0.5 \cup$ GoTaq polymerase (Biotools, Madrid, Spain) and $800 \mathrm{~nm}$ of each primer. After initial incubation for $3 \mathrm{~min}$ at $95^{\circ} \mathrm{C}$, each cycle consisted of $95^{\circ} \mathrm{C}$ for $30 \mathrm{~s}, 55^{\circ} \mathrm{C}$ for $45 \mathrm{~s}$ and $72^{\circ} \mathrm{C}$ for $45 \mathrm{~s}$, for a total of 35 cycles. The RT-PCR products were size-separated on ethidium bromide-stained 2\% agarose gels (PanReact AppliChem, Barcelona, Spain) and a 100-bp DNA ladder was included in each run.

The following primers, obtained from the Instituto de Parasitología y Biomedicina, Granada, Spain, were used:

$\beta 2$-microglobulin ( $\beta 2 \mathrm{MG})$ : 5'-CTCGCGCTACTCTCTCTC TTTCTGG-3' (forward) and 5'-TCTACATGTCTCGATCCC ACTTAA-3' (reverse).

Prolactin: 5'-TTCAGGATGAACCTGGCTGAC-3' (forward) and 5'-GGGTTCATTACCAAGGCCATC-3' (reverse).

\section{Western blot}

To detect proteins, cells were lysed in ice-cold lysis buffer $(140 \mathrm{mM} \mathrm{NaCl}, 10 \mathrm{mM}$ Tris-HCl, 2 M EDTA, 1\% NP-40, 50 $\mathrm{mM} \mathrm{NaF}, 1 \mathrm{mM}$ PMSF, $10 \mathrm{mM}$ iodoacetamide, $5 \mathrm{mM}$ sodium pyrophosphate, $50 \mathrm{mM}$ phenylarsine oxide and protease inhibitors) for $30 \mathrm{~min}$. Proteins in the supernatants were resolved on 10\% SDS-PAGE gels and detected as reported previously (Leno-Duran et al. 2014). Band intensity was quantified with Adobe Photoshop software; intensity values were normalized against the respective loading controls.

\section{Statistical analysis}

All experiments were repeated at least three times with different cell lines. Statistical analysis was carried out using GraphPad Prism 7 software. The data were analyzed with Welch's test for unequal variances. Values of $P<0.05$ were considered significant $\left(* P<0.05,{ }^{*} P<0.01\right.$ and $\left.{ }^{* * *} P<0.001\right)$.

\section{Results}

\section{Antigen phenotype compatible with bone marrow MSC lines in both preEnSC and preDSC lines}

The phenotypic profile of preEnSC lines obtained from menstrual blood showed the characteristic markers previously detected in preDSC lines (Munoz-Fernandez et al. 2018). An extensive, comparative flow cytometric analysis of preEnSC and preDSC lines with a panel of 28 antigens confirmed that both types of cell exhibited an equivalent phenotype, with no statistically significant differences for all the antigens studied. More than $95 \%$ of cells in the preEnSC and preDSC lines expressed CD9, CD10 (an EnSC marker (Sumathi \& McCluggage 2002)), CD13, CD29, CD44, CD73, CD90, $\alpha$-SM actin, nestin and podoplanin and lacked CD15, CD19, CD31, CD34, CD45, CD62P, cytokeratin and HLA-DR expression (Fig. 1 and Table 1). The expression profile for these antigens was equivalent to that observed in bone marrow MSC lines. The exceptions were BAFF and CXCL13, which were expressed by preEnSCs and preDSCs, but not by MSCs (Table 1) (Munoz-Fernandez et al. 2012, Gargett et al. 2016). PreDSC and preEnSC lines also expressed the endometrial MSC (eMSC) markers CD140b, CD146 and SUSD2 (Gargett et al. 2016) (Fig. 1 and Table 1).
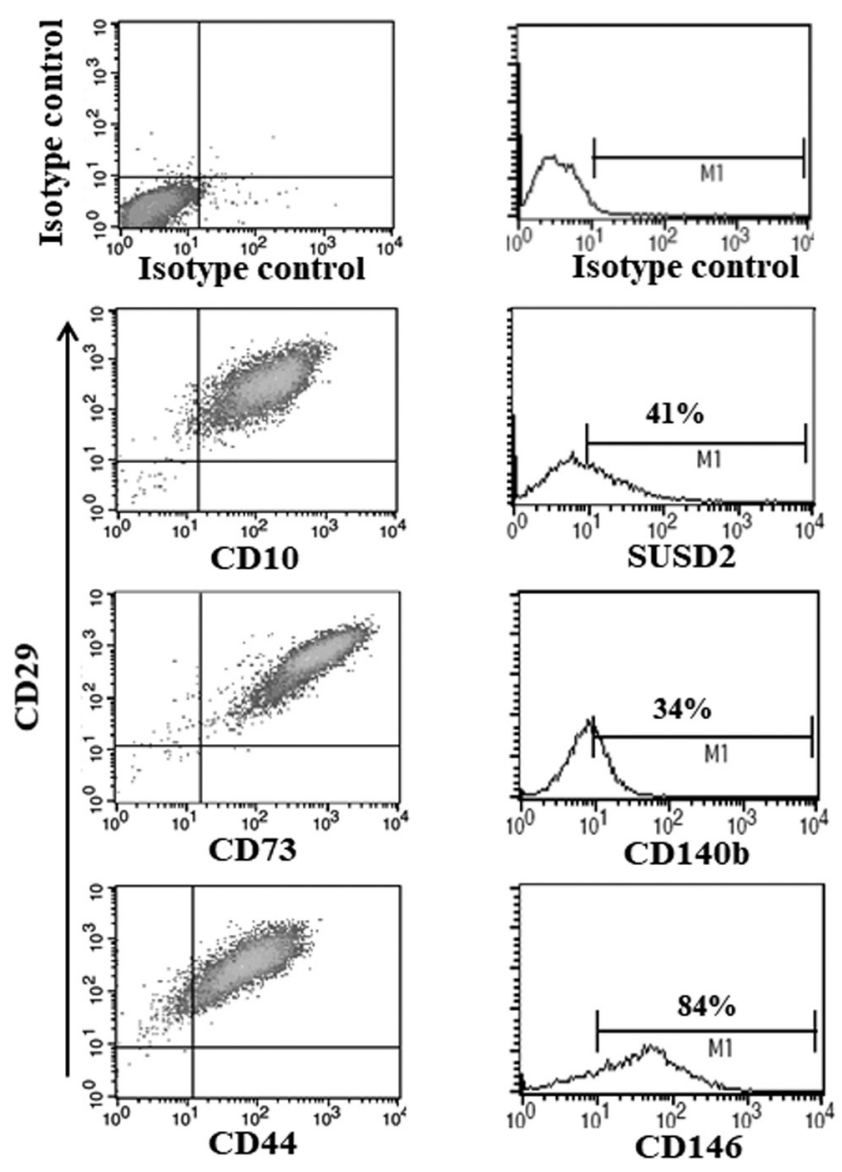

Figure 1 Antigen phenotype of preEnSCs obtained from menstrual blood. Flow cytometry analysis of preEnSC cells stained with antibodies for different cell surface antigens. The figures show the results for a single representative established cell line. 
Table 1 Antigen expression by preEnSC, preDSC and bone marrow MSC lines as determined by flow cytometry.

\begin{tabular}{|c|c|c|c|}
\hline \multirow[b]{2}{*}{ Antigen } & \multicolumn{3}{|c|}{$\%$ Positive cells } \\
\hline & preEnSC $(n=21)$ & $\operatorname{preDSC}(n=20)$ & $\operatorname{MSC}(n=7)$ \\
\hline CD9 & $>95$ & $>95$ & ND \\
\hline CD10 & $>95$ & $>95$ & $>95$ \\
\hline CD13 & $>95$ & $>95$ & $>95$ \\
\hline CD15 & $<1$ & $<1$ & $<1$ \\
\hline CD19 & $<1$ & $<1$ & $<1$ \\
\hline CD29 & $>95$ & $>95$ & $>95$ \\
\hline CD31 & $<1$ & $<1$ & $<1$ \\
\hline CD34 & $<1$ & $<1$ & $<1$ \\
\hline CD44 & $>95$ & $>95$ & $>95$ \\
\hline CD45 & $<1$ & $<1$ & $<1$ \\
\hline CD54 & $75-87$ & $72-91$ & $45-69$ \\
\hline CD62P & $<1$ & $<1$ & $<1$ \\
\hline CD73 & $>95$ & $>95$ & $>95$ \\
\hline CD80 & $5-33$ & $0-73$ & ND \\
\hline CD86 & $10-22$ & $0-79$ & ND \\
\hline CD90 & $>95$ & $>95$ & $>95$ \\
\hline CD106 & $0-22$ & $0-17$ & $0-10$ \\
\hline CD140b & 30-92 & $72-84$ & ND \\
\hline CD146 & $42-85$ & $67-82$ & $68-75$ \\
\hline$\alpha$-SM actin & $>95$ & $>95$ & $>95$ \\
\hline BAFF & $72-84$ & $52-66$ & $<1$ \\
\hline CXCL13 & $18-33$ & $20-32$ & $<1$ \\
\hline Cytokeratin & $<1$ & $<1$ & ND \\
\hline HLA-DR & $<1$ & $<1$ & $<1$ \\
\hline HLA-G & 0-18 & $7-22$ & $<1$ \\
\hline Nestin & $>95$ & $>95$ & $>95$ \\
\hline Podoplanin & $>95$ & $>95$ & $>95$ \\
\hline SUSD2 & $34-79$ & $33-55$ & $21-35$ \\
\hline
\end{tabular}

ND, Not determined.

\section{Stronger evidence of markers and functions associated with decidualization in preDSC lines than in preEnSC lines}

PreDSC and preEnSC lines can differentiate in vitro, as they do in vivo. Under the effect of the decidualizing agents P4 and CAMP, these cells became rounder, secreted PRL and IL-15 and underwent apoptosis (Dunn et al. 2003, Leno-Duran et al. 2014, Sharma et al. 2016).

To further determine whether preDSCs and preEnSCs are equivalent cells, we compared their ability to differentiate in response to P4 and cAMP. Interestingly, while both types of cells changed their fibroblasticlike appearance to a rounder morphology, the percentage of rounded cells was significantly higher in decidualized preDSCs. In addition, decidualized preDSCs secrected significantly more PRL, a widely used marker of decidualization, than decidualized preEnSCs. Other activities associated with the process of decidualization, such as IL-15 production and apoptosis (Dunn et al. 2003, Leno-Duran et al. 2014, Sharma et al. 2016), were also significantly greater in preDSC than in preEnSC lines (Fig. 2). Even after prolonged incubation with $\mathrm{P} 4$ and CAMP, preEnSCs did not reach the level of PRL production and apoptosis observed in preDSCs (Fig. 2B and D). Due to the close relationship of bone marrow MSCs with
preEnSCs and preDSCs (Table 1), we also analyzed MSC lines cultured under decidualizing conditions for comparison. Intriguingly, although MSCs changed their shape to a rounder morphology and expressed PRL mRNA, secretion of this factor was not detected (Supplementary Fig. 1, see section on supplementary materials given at the end of this article).

\section{Expression of progesterone receptor, protein kinase $A$ and FOXO1 in preEnSCs and preDSCs}

The nuclear receptors for progesterone (PR) and protein kinase A (PKA)-mediated CAMP signaling are crucial for decidualization (Brar et al. 1997, Telgmann et al. 1997, Kaya et al. 2015). The progesterone receptor has two isoforms, PR-A and PR-B, whereas in the case of PKA, an enzymatic complex formed by two regulatory $(R)$ and two catalytic (C) subunits, three distinct $C$ subunits

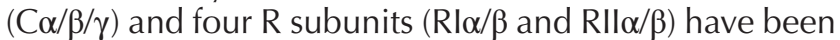
identified (Skalhegg \& Tasken 2000). It has been reported that EnSCs express the $C \alpha$ and $C \beta$ isoforms as well as all four regulatory subunits of PKA, although expression of the Rlo isoform is higher than the rest (Telgmann et al. 1997, Kim et al. 1998). We compared the expression of PR and PKA between preEnSC and preDSC. As shown in Fig. 3A, both types of cells showed similar basal levels of the two isoforms of PR and the catalytic $(C \alpha / \beta / \gamma)$ and $l \alpha / \beta$ regulatory $(R \mid \alpha / \beta)$ subunits of PKA. In addition, expression of the regulatory subunit of PKA and the PR-A isoform increased after decidualization in both cell types. Interestingly, upregulation of PKA RI $\alpha / \beta$ was significantly higher in decidualized preDSCs than in decidualized preEnSCs (Fig. 3A, right panel). These results were confirmed by a time course expression analysis of PKA RI $\alpha / \beta$ in response to decidualization (Fig. 3B). We further explored differences in the signaling pathways in response to decidualization by analyzing the expression of the transcription factor FOXO1, a downstream mediator of decidualizing factors (Buzzio et al 2006, Labied et al 2006). As expected, incubation with $\mathrm{P} 4$ and cAMP induced the expression of FOXO1 in preEnSC and preDSC but without significant differences between both cell types (Fig. 3A).

\section{Discussion}

There is considerable confusion in the terminology regarding EnSCs and DSCs. Because the endometrium differentiates into decidua when gestation occurs, some authors consider EnSCs as precursor cells and DSCs as differentiated cells. The fact that decidualization has been observed in vivo and in vitro, in both the endometrium and decidua (Wynn 1974, Ferenczy \& Guralnick 1983, Huang et al. 1987, Olivares et al. 1997), indicates that there must be precursor cells in both tissues, which we have called preEnSCs and preDSCs, respectively (Olivares et al. 1997). These two 
types of precursors may be considered the same type of cell in two different physiological situations, that is, nongestation and gestation. In fact, our analysis of the expression of 35 antigens showed an equivalent antigen phenotype for both precursors (Fig. 1 and Table 1). However, we observed that processes associated with decidualization, for example, change in the cellular morphology to a rounder shape, secretion of PRL and IL-15 and apoptosis (Dunn et al. 2003, Leno-Duran et al. 2014, Sharma et al. 2016), were significantly more evident in preDSCs than in preEnSCs (Fig. 2). To our knowledge, this is the first study designed to compare markers of decidualization processes in preEnSCs and preDSCs.

Our results could be attributed to the fact that we compared stromal cells from a wasting tissue (menstrual blood) to stromal cells from a developing tissue (decidua). However, although normal menstrual blood and decidua harbor apoptotic cells (Tabibzadeh 1996, von Rango et al. 1998), the cell cultures developed to establish cell lines select only healthy, proliferative cells to survive, which correspond to precursor cells in both tissues (Meng et al. 2007, Hida et al. 2008, Patel et al. 2008, Munoz-Fernandez et al. 2019). In this connection, stromal cells from menstrual blood and decidua have been used in numerous basic and clinical studies (Hida et al. 2008, Zhong et al. 2009, Ulrich et al. 2013, Sugawara et al. 2014, Alshabibi et al. 2018, Sadeghi et al. 2019). Furthermore, a similar antigen phenotype and capacity to decidualize were observed in preEnSC lines obtained from endometrial biopsies rather than menstrual blood (Supplementary Fig. 2). Because menstrual blood is easily obtained by noninvasive methods, it was used as the source of endometrial stromal cells in our study.
Decidualized cells depend on the constant activation of cAMP-dependent PKA for the efficient expression of their characteristic phenotype and markers, including PRL. Earlier work found that, after decidualization with $17 \beta$-estradiol, MPA (medroxyprogesterone acetate) and relaxin, there were no differences in the expression of the PKA subunits except for the Rlo isoform, which was downregulated at the protein level (Telgmann et al. 1997, Kim et al. 1998). In the present work, we compared the expression of the $\mathrm{C}$ and RI subunits in preEnSCs and preDSCs and found that both types of cells showed similar levels of these proteins. This finding confirmed that decidualization did not regulate the expression of PKA C. Interestingly, we found that PKA RI was upregulated after treatment with P4 and cAMP. Both decidualized EnSCs and DSCs maintained high levels of PKA RI expression throughout the time course studied here, although the increase was significantly greater in DSCs. The discrepancies between our data and those of Telgmann et al. may be due to the different experimental conditions used to establish, maintain and decidualize cell lines (Telgmann et al. 1997). Because PKA formed by RI subunits was reportedly a more efficient activator of cAMP-responsive elements than PKA that contained RII (Stakkestad et al. 2011), the larger increase in RI in preDSCs may explain their greater ability to decidualize. In addition to PKA, we also analyzed the expression of PR as the other key mediator of decidualization signaling. Our results show that there was no difference between preDSCs and preEnSCs in either the basal expression of $\mathrm{PR}$ or the increase in the PR-A isoform in response to decidualization, suggesting that the different behaviors in the two cell types may not be due to differences at this stage of progesterone signaling. Moreover, the downstream mediator FOXO1, which has been reported

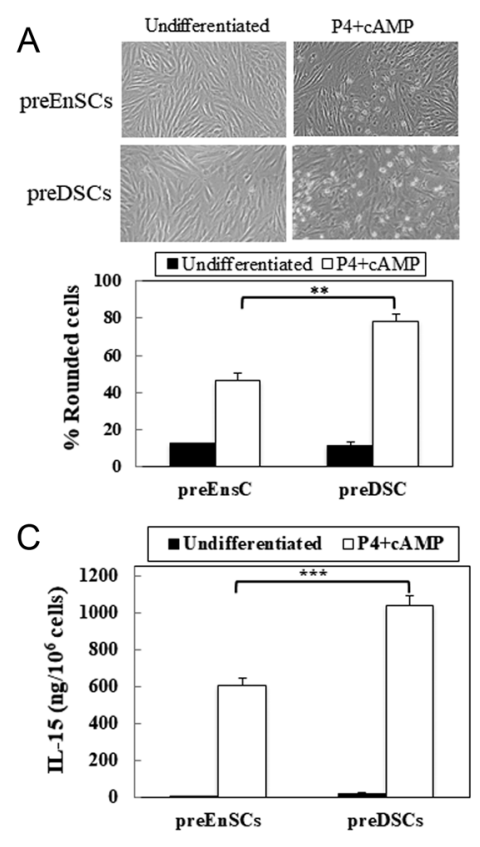

https://rep.bioscientifica.com
B
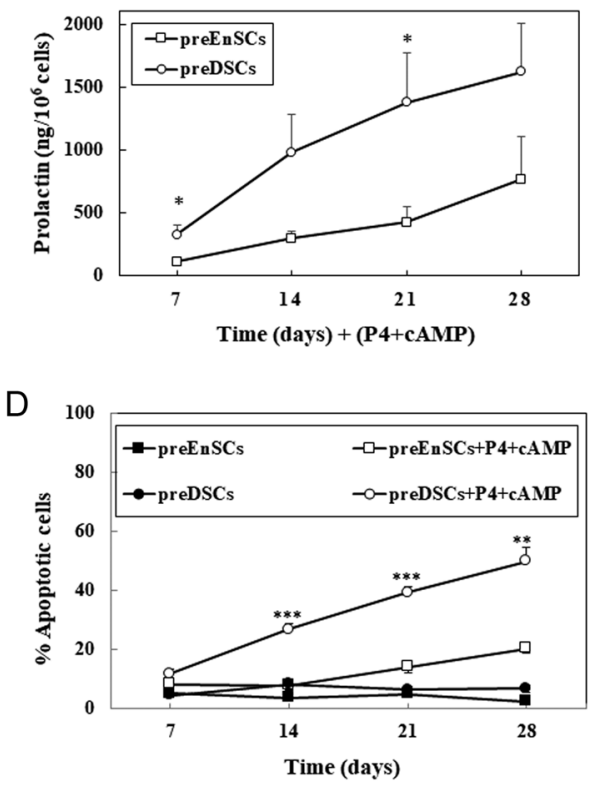

Figure 2 Comparative analysis of decidualized EnSCs and DSCs. (A) Morphological changes in undifferentiated preEnSCs and preDSCs after 7 days of culture with P4 and cAMP. Bars show the percentage of rounded cells after quantification of representative areas $(n=3$ per sample) with ImageJ. (B) Time course of PRL secretion by preEnSCs and preDSCs after incubation with P4 and CAMP. PRL production by nondecidualized (undifferentiated) cells was zero at all time points (not shown). (C) Secretion of IL-15 after 7 days of culture without (undifferentiated) or with $\mathrm{P} 4$ and cAMP. (D) Induction of apoptosis upon incubation without (undifferentiated) or with P4 and cAMP for up to 28 days. Sub-G1 apoptotic cells were analyzed every 7 days. Error bars show the S.E.M. of five (B and D) and three $(A$ and $C$ ) independent experiments with different cell lines. ${ }^{*} P<0.05,{ }^{* *} P<0.01$ and $* * * P<0.001$ (preEnSC + P4 + cAMP vs preDSC + P4 + CAMP). 

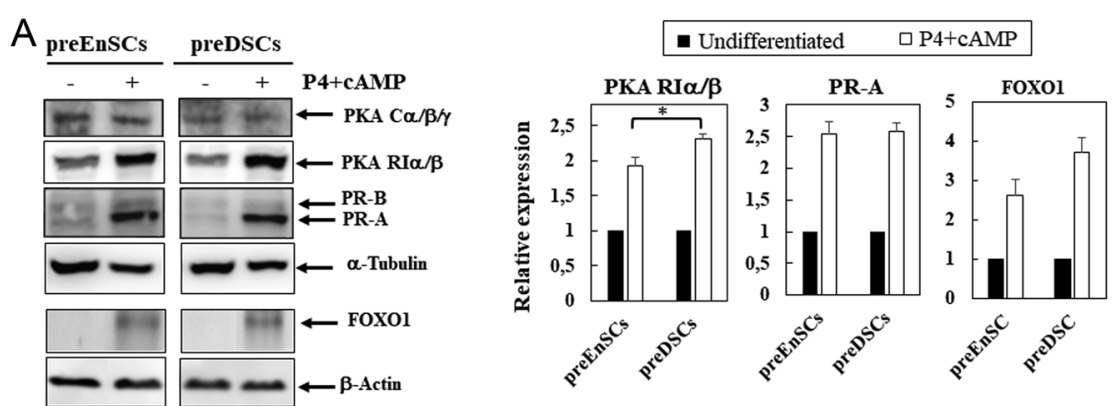

B

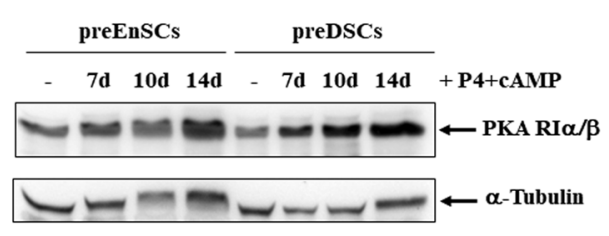

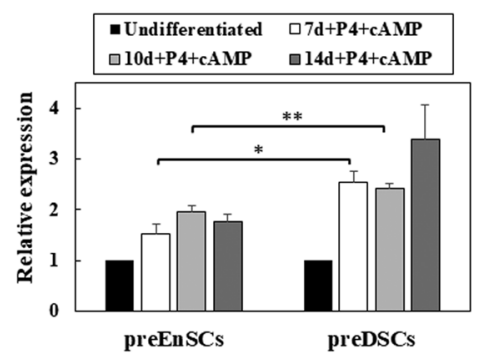

Figure 3 Expression of PR, PKA and FOXO1 in response to decidualization. (A) preEnSCs and preDSCs were incubated with $\mathrm{P} 4$ and CAMP for 10 days, and the expression of PR isoforms, PKA catalytic $(\mathrm{C} \alpha / \beta / \gamma)$ and regulatory $(\mathrm{RI} \alpha / \beta)$ subunits and FOXO1 was determined by Western blot. (B) Expression of PKA RI $\alpha / \beta$ was analyzed by Western blot in preEnSCs and preDSCs after incubation for 7, 10 and 14 days with P4 + cAMP. $\alpha$-tubulin and $\beta$-actin were used as controls for loaded protein. A representative experiment is shown (left panels). Bar charts show the relative expression of PR-A (A), PKA RI $\alpha / \beta$ (A, B) and FOXO1 (A) after band intensity analysis from three different Western blots (right panels). to play a role in the differentiation of endometrial cells (Buzzio et al. 2006, Labied et al. 2006, Kajihara et al. 2013), did not seem to be involved in the different response of preEnSCs and preDSCs to decidualization.

Gestation is an immunological challenge for the mother, and several lines of experimental evidence support the key role of DSCs in maintaining immunological tolerance to avoid rejection of the fetus (Dunn et al. 2003, Blanco et al. 2008, 2009, Munoz-Fernandez et al. 2012, Nancy et al. 2012). The production of IL-15 by decidualized cells appears to be related to the maintenance of decidual NK cells (Dunn et al. 2003). Concerning apoptosis, this was previously reported to occur in parallel with decidualization, as a physiological phenomenon necessary to limit the lifespan of DSCs and allow placental development to proceed (Leno-Duran et al. 2014). Conversely, in the absence of gestation, these activities do not necessarily need to be carried out by EnSCs, although these cells are 'standing by' in case pregnancy takes place. Although the findings available to date regarding antigen phenotype, perivascular location, relation to MSCs and secreted factors support that preEnSCs and preDSCs are the same type of cell, they are nevertheless located in two different physiological milieus: nongestational and gestational, respectively. Furthermore, preDSCs remain in vivo for a longer period (up to 11 weeks of gestation before the voluntary termination of pregnancy) than preEnSCs (up to 4 weeks before menstruation) before they can be isolated to establish cell lines. These distinct milieus, which involve a different environment in terms of cytokines, hormones and growth factors, together with differences in their natural history, are the probable causes of the differences observed between preEnSCs and preDSCs, as suggested by others (Kyurkchiev et al. 2010). Because decidualization is a complex phenomenon, further research is necessary to understand the molecules involved in this process as well as the genetic or epigenetic factors that, under the influence of the milieu, may regulate the likelihood of decidualization.

In previous publications, we and others demonstrated the close relationships between preEnSCs, preDSCs and MSCs (Dimitrov et al. 2008, 2010, Munoz-Fernandez et al. 2012, 2018, 2019). Our present results, which show that both types of precursor - one from the endometrium, and one from the decidua - have an antigen phenotype in common with bone marrow MSCs (Table 1), confirm these relationships and support the view proposed by some authors (Taylor 2004, Du \& Taylor 2007) that bone marrow-derived MSCs may be the source of EnSCs and hence of DSCs. Despite the close relationships among preEnSCs, preDSCs and bone marrow MSCs, we detected differences in the expression of BAFF and CXCL13, which was positive in preEnSCs and preDSCs but negative in MSCs. These differences may be due to the immunological interactions of bone marrow MSCs, when they arrive in the endometrium or decidua, with local immune cells (Vacca et al. 2015). Furthermore, bone marrow MSCs demonstrated a low capacity to decidualize, given that they did not secrete PRL in response to P4 and cAMP (Supplementary Fig. 1). Our results suggest that through a gradual process of progression from MSCs (bone marrow) to preEnSCs (endometrium) and then to preDSCs (decidua), stromal cells acquire the decidualization capacity essential for the normal development of pregnancy (Dunn et al. 2003). Thus, further elucidation of the initiation and progression of decidualization capacity may help to better understand diseases such as endometriosis, in which cells are unable to decidualize (Patel et al. 2017). 
PreDSCs and preEnSCs also appear to correspond to endometrial MSCs (eMSCs), that is, clonogenic, selfrenewing, multipotent cells that can differentiate into adipogenic, osteogenic, chondrogenic and myogenic lineages. eMSCs, similar to preDSCs and preEnSCs, also express CD140b, CD146 and SUSD2, decidualize, are located around the vessels, and have been associated with pericytes (Gargett \& Masuda 2010, Kyurkchiev et al. 2010, Spitzer et al. 2012, Munoz-Fernandez et al. 2018). However, to date, eMSCs have been isolated only by cell sorting, whereas the preEnSC and preDSC lines obtained in the present work from endometrium and decidua were enriched by cell culture.

Like MSCs (Uccelli et al. 2008), preDSCs and preEnSCs exhibit immunoregulatory activity in vivo and in vitro (Vacca et al. 2015). Human DSCs were found to have beneficial effects in steroid-refractory graft-vshost disease in humans (Ringden et al. 2013, 2018). Likewise, we recently demonstrated the therapeutic effect of human preDSCs in an immune-based mouse model of recurrent spontaneous abortion (MunozFernandez et al. 2019). These findings identify DSCs, and probably EnSCs, as potentially important components of cell therapies for immune-mediated diseases. The availability of endometrial and decidual stromal cells, and the straightforward techniques needed to purify and expand them, may help to further research on their clinical applications in the treatment of autoimmune and inflammatory diseases. Our findings thus raise the possibility of testing DSCs and EnSCs in therapeutic trials to determine which cell type would be more suitable (Simoni \& Taylor 2018, Queckborner et al. 2019).

In conclusion, our results suggest that although stromal precursors from endometrium and decidua have a similar phenotype, they differ in their response to decidualization factors, with preDSCs being significantly more responsive. The similarity of these precursors with MSCs suggests an important therapeutic potential for inflammatory diseases.

\section{Supplementary materials}

This is linked to the online version of the paper at https://doi. org/10.1530/REP-19-0465.

\section{Declaration of interest}

The authors declare that there is no conflict of interest that could be perceived as prejudicing the impartiality of the research reported.

\section{Funding}

This work was supported by the Plan Estatal de Investigación Científica y Técnica y de Innovación 2013-2016, ISCIIISubdirección General de Evaluación y Fomento de la
Investigación, Ministerio de Economía y Competitividad, Spain (Grant PI16/01642), by ERDF/FEDER Funds, European Community and by the Cátedra de Investigación Antonio Chamorro-Alejandro Otero, Universidad de Granada (CACH2017-1). This article contributes to the COST Action CA17116 'International Network for Translating Research on Perinatal Derivatives into Therapeutic Approaches (SPRINT)', supported by COST (European Cooperation in Science and Technology).

\section{Author contribution statement}

M J R M contributed to the conception and design, administrative support, collection and/or assembly of data, experimental procedures, data analysis and interpretation and final approval of manuscript. J M P contributed to administrative support, collection and/or assembly of data, experimental procedures, data analysis and interpretation and final approval of manuscript. $\mathrm{R} \mathrm{M} \mathrm{A} \mathrm{contributed} \mathrm{to}$ administrative support, collection and/or assembly of data, experimental procedures, data analysis and interpretation and final approval of manuscript. T L contributed to the collection and/or assembly of data, experimental procedures, data analysis and interpretation and final approval of manuscript. $\mathrm{O}$ B performed collection and/or assembly of data, experimental procedures, data analysis and interpretation and final approval of manuscript. R M F contributed to the collection and/or assembly of data, experimental procedures, data analysis and interpretation and final approval of manuscript. E G O contributed to the conception and design, financial support, provision of study material or patients, collection and/or assembly of data, data analysis and interpretation, manuscript writing and final approval of manuscript. C R-R contributed to the conception and design, financial support, provision of study material or patients, collection and/or assembly of data, data analysis and interpretation, manuscript writing and final approval of manuscript. E G O and C R-R jointly supervised this work.

\section{Acknowledgements}

This article contributes to COST Action CA17116 'International Network for Translating Research on Perinatal Derivatives into Therapeutic Approaches (SPRINT)', supported by COST (European Cooperation in Science and Technology). The authors are grateful to Dr S Jordán from Clínica el Sur (Malaga, Spain) and Dr F García Gallego from Clínica Ginegranada (Granada, Spain) for providing them with decidual specimens. The authors thank K Shashok for improving the use of English in the manuscript.

\section{References}

Alshabibi MA, Khatlani T, Abomaray FM, Alaskar AS, Kalionis B, Messaoudi SA, Khanabdali R, Alawad AO \& Abumaree MH 2018 Human decidua basalis mesenchymal stem/stromal cells protect endothelial cell functions from oxidative stress induced by hydrogen peroxide and monocytes. Stem Cell Research and Therapy 9 275. (https://doi. org/10.1186/s13287-018-1021-z) 
Bergeron C 2000 Morphological changes and protein secretion induced by progesterone in the endometrium during the luteal phase in preparation for nidation. Human Reproduction 15 (Supplement 1) 119-128. (https:// doi.org/10.1093/humrep/15.suppl_1.119)

Blanco O, Tirado I, Munoz-Fernandez R, Abadia-Molina AC, GarciaPacheco JM, Pena J \& Olivares EG 2008 Human decidual stromal cells express HLA-G: effects of cytokines and decidualization. Human Reproduction 23 144-152. (https://doi.org/10.1093/humrep/dem326)

Blanco O, Leno-Duran E, Morales JC, Olivares EG \& Ruiz-Ruiz C 2009 Human decidual stromal cells protect lymphocytes from apoptosis. Placenta 30 677-685. (https://doi.org/10.1016/j.placenta.2009.05.011)

Brar AK, Frank GR, Kessler CA, Cedars MI \& Handwerger S 1997 Progesterone-dependent decidualization of the human endometrium is mediated by CAMP. Endocrine 6 301-307. (https://doi.org/10.1007/ BF02820507)

Buzzio OL, Lu Z, Miller CD, Unterman TG \& Kim JJ 2006 FOXO1A differentially regulates genes of decidualization. Endocrinology 147 3870-3876. (https://doi.org/10.1210/en.2006-0167)

Caplan Al \& Correa D 2011 The MSC: an injury drugstore. Cell Stem Cell 9 11-15. (https://doi.org/10.1016/j.stem.2011.06.008)

Da Silva Meirelles L, Caplan AI \& Nardi NB 2008 In search of the in vivo identity of mesenchymal stem cells. Stem Cells 26 2287-2299. (https:// doi.org/10.1634/stemcells.2007-1122)

Da Silva Meirelles L, Malta TM, Panepucci RA \& Da Silva Jr WA 2016 Transcriptomic comparisons between cultured human adipose tissuederived pericytes and mesenchymal stromal cells. Genomics Data 7 20-25. (https://doi.org/10.1016/j.gdata.2015.11.009)

Dimitrov R, Timeva T, Kyurkchiev D, Stamenova M, Shterev A, Kostova P Zlatkov V, Kehayov I \& Kyurkchiev S 2008 Characterization of clonogenic stromal cells isolated from human endometrium. Reproduction 135 551-558. (https://doi.org/10.1530/REP-07-0428)

Dimitrov R, Kyurkchiev D, Timeva T, Yunakova M, Stamenova M, Shterev A \& Kyurkchiev S 2010 First-trimester human decidua contains a population of mesenchymal stem cells. Fertility and Sterility 93 210-219. (https://doi.org/10.1016/j.fertnstert.2008.09.061)

Du H \& Taylor HS 2007 Contribution of bone marrow-derived stem cells to endometrium and endometriosis. Stem Cells 25 2082-2086. (https://doi. org/10.1634/stemcells.2006-0828)

Dunn CL, Kelly RW \& Critchley HO 2003 Decidualization of the human endometrial stromal cell: an enigmatic transformation. Reproductive Biomedicine Online 7 151-161. (https://doi.org/10.1016/s1472 6483(10)61745-2)

Ferenczy A \& Guralnick M 1983 Endometrial microstructure: structure-function relationships throughout the menstrual cycle. Seminars in Reproductive Medicine 1 205-219. (https://doi. org/10.1055/s-2008-1067956)

Garcia-Pacheco JM, Oliver C, Kimatrai M, Blanco FJ \& Olivares EG 2001 Human decidual stromal cells express CD34 and STRO-1 and are related to bone marrow stromal precursors. Molecular Human Reproduction 7 1151-1157. (https://doi.org/10.1093/molehr/7.12.1151)

Gargett CE \& Masuda H 2010 Adult stem cells in the endometrium. Molecular Human Reproduction 16 818-834. (https://doi.org/10.1093/ molehr/gaq061)

Gargett CE, Schwab KE \& Deane JA 2016 Endometrial stem/progenitor cells: the first 10 years. Human Reproduction Update 22 137-163. (https://doi.org/10.1093/humupd/dmv051)

Hida N, Nishiyama N, Miyoshi S, Kira S, Segawa K, Uyama T, Mori T, Miyado K, Ikegami Y, Cui C et al. 2008 Novel cardiac precursor-like cells from human menstrual blood-derived mesenchymal cells. Stem Cells 26 1695-1704. (https://doi.org/10.1634/stemcells.2007-0826)

Huang JR, Tseng L, Bischof P \& Janne OA 1987 Regulation of prolactin production by progestin, estrogen, and relaxin in human endometrial stromal cells. Endocrinology 121 2011-2017. (https://doi.org/10.1210/ endo-121-6-2011)

Kajihara T, Brosens JJ \& Ishihara O 2013 The role of FOXO1 in the decidual transformation of the endometrium and early pregnancy. Medical Molecular Morphology 46 61-68. (https://doi.org/10.1007/s00795-0130018-z)

Kaya HS, Hantak AM, Stubbs LJ, Taylor RN, Bagchi IC \& Bagchi MK 2015 Roles of progesterone receptor A and B isoforms during human endometrial decidualization. Molecular Endocrinology 29 882-895. (https://doi.org/10.1210/me.2014-1363)
Kim JJ, Jaffe RC \& Fazleabas AT 1998 Comparative studies on the in vitro decidualization process in the baboon (Papio anubis) and human. Biology of Reproduction 59 160-168. (https://doi.org/10.1095/ biolreprod59.1.160)

Kimatrai M, Oliver C, Abadia-Molina AC, Garcia-Pacheco JM \& Olivares EG 2003 Contractile activity of human decidual stromal cells. Journal of Clinical Endocrinology and Metabolism 88 844-849. (https:// doi.org/10.1210/jc.2002-021224)

Kimatrai M, Blanco O, Munoz-Fernandez R, Tirado I, Martin F, AbadiaMolina AC \& Olivares EG 2005 Contractile activity of human decidual stromal cells. II. Effect of interleukin-10. Journal of Clinical Endocrinology and Metabolism 90 6126-6130. (https://doi.org/10.1210/jc.2005-0047)

Kyurkchiev S, Shterev A \& Dimitrov R 2010 Assessment of presence and characteristics of multipotent stromal cells in human endometrium and decidua. Reproductive Biomedicine Online 20 305-313. (https://doi. org/10.1016/j.rbmo.2009.12.011)

Labied S, Kajihara T, Madureira PA, Fusi L, Jones MC, Higham JM, Varshochi R, Francis JM, Zoumpoulidou G, Essafi A et al. 2006 Progestins regulate the expression and activity of the forkhead transcription factor FOXO1 in differentiating human endometrium. Molecular Endocrinology 20 35-44. (https://doi.org/10.1210/me.2005-0275)

Leno-Duran E, Ruiz-Magana MJ, Munoz-Fernandez R, Requena $F$, Olivares EG. \& Ruiz-Ruiz C 2014 Human decidual stromal cells secrete soluble pro-apoptotic factors during decidualization in a CAMPdependent manner. Human Reproduction 29 2269-2277. (https://doi. org/10.1093/humrep/deu202)

Meng X, Ichim TE, Zhong J, Rogers A, Yin Z, Jackson J, Wang H, Ge W, Bogin V, Chan KW et al. 2007 Endometrial regenerative cells: a novel stem cell population. Journal of Translational Medicine 5 57. (https://doi. org/10.1186/1479-5876-5-57)

Munoz-Fernandez R, Prados A, Leno-Duran E, Blazquez A, GarciaFernandez JR, Ortiz-Ferron G \& Olivares EG 2012 Human decidual stromal cells secrete C-X-C motif chemokine 13, express B cellactivating factor and rescue $\mathrm{B}$ lymphocytes from apoptosis: distinctive characteristics of follicular dendritic cells. Human Reproduction 27 2775-2784. (https://doi.org/10.1093/humrep/des198)

Munoz-Fernandez R, de la Mata C, Prados A, Perea A, Ruiz-Magana MJ, Llorca T, Fernandez-Rubio P, Blanco O, Abadia-Molina AC \& Olivares EG 2018 Human predecidual stromal cells have distinctive characteristics of pericytes: cell contractility, chemotactic activity, and expression of pericyte markers and angiogenic factors. Placenta 61 39-47. (https://doi. org/10.1016/j.placenta.2017.11.010)

Munoz-Fernandez R, de la Mata C, Requena F, Martin F, FernandezRubio P, Llorca T, Ruiz-Magana MJ, Ruiz-Ruiz C \& Olivares EG 2019 Human predecidual stromal cells are mesenchymal stromal/stem cells and have a therapeutic effect in an immune-based mouse model of recurrent spontaneous abortion. Stem Cell Research and Therapy 10 177. (https://doi.org/10.1186/s13287-019-1284-z)

Nancy P, Tagliani E, Tay CS, Asp P, Levy DE \& Erlebacher A 2012 Chemokine gene silencing in decidual stromal cells limits T cell access to the maternal-fetal interface. Science 336 1317-1321. (https://doi. org/10.1126/science.1220030)

Olivares EG, Montes MJ, Oliver C, Galindo JA \& Ruiz C 1997 Cultured human decidual stromal cells express B7-1 (CD80) and B7-2 (CD86) and stimulate allogeneic T cells. Biology of Reproduction 57 609-615. (https://doi.org/10.1095/biolreprod57.3.609)

Oliver C, Montes MJ, Galindo JA, Ruiz C \& Olivares EG 1999 Human decidual stromal cells express alpha-smooth muscle actin and show ultrastructural similarities with myofibroblasts. Human Reproduction $\mathbf{1 4}$ 1599-1605. (https://doi.org/10.1093/humrep/14.6.1599)

Patel AN, Park E, Kuzman M, Benetti F, Silva FJ \& Allickson JG 2008 Multipotent menstrual blood stromal stem cells: isolation, characterization, and differentiation. Cell Transplantation 17 303-311. (https://doi.org/10.3727/096368908784153922)

Patel BG, Rudnicki M, Yu J, Shu Y \& Taylor RN 2017 Progesterone resistance in endometriosis: origins, consequences and interventions. Acta Obstetricia et Gynecologica Scandinavica 96 623-632. (https://doi. org/10.1111/aogs.13156)

Queckborner S, Davies LC, von Grothusen C, Santamaria X, Simon C \& Gemzell-Danielsson K 2019 Cellular therapies for the endometrium: an update. Acta Obstetricia et Gynecologica Scandinavica 98 672-677. (https://doi.org/10.1111/aogs.13598) 
Ringden O, Erkers T, Nava S, Uzunel M, Iwarsson E, Conrad $R$ Westgren M, Mattsson J \& Kaipe H 2013 Fetal membrane cells for treatment of steroid-refractory acute graft-versus-host disease. Stem Cells 31 592-601. (https://doi.org/10.1002/stem.1314)

Ringden O, Baygan A, Remberger M, Gustafsson B, Winiarski J, Khoein B, Moll G, Klingspor L, Westgren M \& Sadeghi B 2018 Placenta-derived decidua stromal cells for treatment of severe acute graft-versus-host disease. Stem Cells Translational Medicine 7 325-331. (https://doi. org/10.1002/sctm.17-0167)

Sadeghi B, Remberger M, Gustafsson B, Winiarski J, Moretti G, Khoein B, Klingspor L, Westgren M, Mattsson J \& Ringden O 2019 Long-term followup of a pilot study using placenta-derived decidua stromal cells for severe acute graft-versus-host disease. Biology of Blood and Marrow Transplantation 25 1965-1969. (https://doi.org/10.1016/j.bbmt.2019.05.034)

Sharma S, Godbole G \& Modi D 2016 Decidual control of trophoblast invasion. American Journal of Reproductive Immunology 75 341-350. (https://doi.org/10.1111/aji.12466)

Simoni M \& Taylor HS 2018 Therapeutic strategies involving uterine stem cells in reproductive medicine. Current Opinion in Obstetrics and Gynecology 30 209-216. (https://doi.org/10.1097/ GCO.0000000000000457)

Skalhegg BS \& Tasken K 2000 Specificity in the CAMP/PKA signaling pathway. Differential expression, regulation, and subcellular localization of subunits of PKA. Frontiers in Bioscience 5 D678-D693. (https://doi. org/10.2741/skalhegg)

Spitzer TL, Rojas A, Zelenko Z, Aghajanova L, Erikson DW, Barragan F, Meyer M, Tamaresis JS, Hamilton AE, Irwin JC et al. 2012 Perivascular human endometrial mesenchymal stem cells express pathways relevant to self-renewal, lineage specification, and functional phenotype. Biology of Reproduction 86 58. (https://doi.org/10.1095/biolreprod.111.095885)

Stakkestad Ø, Larsen AC, Kvissel AK, Eikvar S, Orstavik S \& Skalhegg BS 2011 Protein kinase A type I activates a CRE-element more efficiently than protein kinase $\mathrm{A}$ type II regardless of $\mathrm{C}$ subunit isoform. BMC Biochemistry 12 7. (https://doi.org/10.1186/1471-2091-12-7)

Sugawara K, Hamatani T, Yamada M, Ogawa S, Kamijo S, Kuji N, Akutsu H, Miyado K, Yoshimura Y \& Umezawa A 2014 Derivation of human decidua-like cells from amnion and menstrual blood. Scientific Reports 4 4599. (https://doi.org/10.1038/srep04599)

Sumathi VP \& Mccluggage WG 2002 CD10 is useful in demonstrating endometrial stroma at ectopic sites and in confirming a diagnosis of endometriosis. Journal of Clinical Pathology 55 391-392. (https://doi. org/10.1136/jcp.55.5.391)

Tabibzadeh S 1996 The signals and molecular pathways involved in human menstruation, a unique process of tissue destruction and remodelling.
Molecular Human Reproduction 2 77-92. (https://doi.org/10.1093/ molehr/2.2.77)

Taylor HS 2004 Endometrial cells derived from donor stem cells in bone marrow transplant recipients. JAMA 292 81-85. (https://doi.org/10.1001/ jama.292.1.81)

Telgmann R \& Gellersen B 1998 Marker genes of decidualization: activation of the decidual prolactin gene. Human Reproduction Update 4 472-479. (https://doi.org/10.1093/humupd/4.5.472)

Telgmann R, Maronde E, Tasken K \& Gellersen B 1997 Activated protein kinase $A$ is required for differentiation-dependent transcription of the decidual prolactin gene in human endometrial stromal cells. Endocrinology 138 929-937. (https://doi.org/10.1210/endo.138.3.5004)

Uccelli A, Moretta L \& Pistoia V 2008 Mesenchymal stem cells in health and disease. Nature Reviews: Immunology 8 726-736. (https://doi. org/10.1038/nri2395)

Ulrich D, Muralitharan R \& Gargett CE 2013 Toward the use of endometrial and menstrual blood mesenchymal stem cells for cell-based therapies. Expert Opinion on Biological Therapy 13 1387-1400. (https://doi.org/10 1517/14712598.2013.826187)

Vacca P, Montaldo E, Vitale C, Croxatto D, Moretta L \& Mingari MC 2015 MSC and innate immune cell interactions: a lesson from human decidua. Immunology Letters 168 170-174. (https://doi.org/10.1016/j. imlet.2015.05.006)

von Rango U, Classen-Linke I, Krusche CA \& Beier HM 1998 The receptive endometrium is characterized by apoptosis in the glands. Human Reproduction 13 3177-3189. (https://doi.org/10.1093/ humrep/13.11.3177)

Wynn RM 1974 Ultrastructural development of the human decidua. American Journal of Obstetrics and Gynecology 118 652-670. (https:// doi.org/10.1016/s0002-9378(16)33740-1)

Zhong Z, Patel AN, Ichim TE, Riordan NH, Wang H, Min WP, Woods EJ, Reid M, Mansilla E, Marin GH et al. 2009 Feasibility investigation of allogeneic endometrial regenerative cells. Journal of Translational Medicine 7 15. (https://doi.org/10.1186/1479-5876-7-15)

Received 29 September 2019

First decision 1 November 2019

Revised manuscript received 2 April 2020

Accepted 17 April 2020 